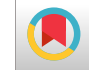

\title{
Assessing Breast Cancer Knowledge Among Iranian Physicians
}

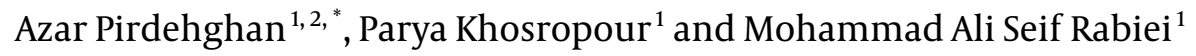 \\ ${ }^{1}$ Department of Community and Preventive Medicine, Hamadan University of Medical Sciences, Hamadan, Iran \\ ${ }^{2}$ Research Center for Health Sciences, School of Public Health, Hamadan University of Medical Sciences, Hamadan, Iran \\ "Corresponding author: Department of Community and Preventive Medicine, Hamadan University of Medical Sciences, Hamadan, Iran. Tel: +98-8138380572, Email: \\ pirdehghan93@gmail.com
}

Received 2018 October 28; Revised 2019 March 10; Accepted 2019 April 10.

\begin{abstract}
Background: Breast cancer (BC) is one of the most important public health issues; so, knowledge about signs, symptoms, and screening programs has impressive role in $\mathrm{BC}$ prevention.

Objectives: The objective of this study was measuring general physician's knowledge regarding BC screening programs.

Methods: This cross sectional study was performed among 200 general physicians (GP) of urban and rural areas from Jun to September, 2017 in Hamadan, Iran, using a self-administered semi-structured questionnaire. The data were analyzed by SPSS. Significance level was set at $\mathrm{P}<0.05$.

Results: The mean score of total knowledge on breast cancer screening, risk factors, signs, and symptoms for 23 questions was 15.07 \pm 2.4 (max: 20; min: 9), which meant that correct answers were given to more than half of them. In symptom knowledge area, $45.3 \%$ of physicians had correct answer to 4 questions, whereas about risk factor, $61.4 \%$ recorded correct answer to 8 questions. There was a significant reverse correlation between knowledge about screening programs and age of participants $(\mathrm{r}=-0.3 ; \mathrm{P}<0.001)$, and their years of work experience $(\mathrm{r}=-0.26 ; \mathrm{P}<0.001)$.

Conclusions: In the current study, family physician knowledge on breast cancer signs, symptom, and screening programs was insufficient. It is recommended that there should be a well-designed health education program to compensate physicians' knowledge deficits, especially in older ages in order to raise awareness toward cancer, with emphasis on the role of prevention and screening. Importance of early diagnosis in breast cancer and its high rate in our country are adequate reasons for considering this issue on top of our priorities.
\end{abstract}

Keywords: Breast Cancer, Early Detection of Cancer, Awareness

\section{Background}

Breast cancer $(\mathrm{BC})$ is one of the most public health issues in Iran and worldwide (1-3). In low and middle income countries, its growth rate was up to $5 \%$ per year (4).

In Iran, BC is known as the most common cancer in women after skin cancer $(5,6)$. The Iran Ministry of Health estimated that the incidence of breast cancer in women was 22 per 100000 and the prevalence in this same population was 120 per 100000 (7). In recent review, 65.5\% to $70.5 \%$ of breast cancer cases were in the early stages ( 1 and 2) and less than $30 \%$ were in the advanced stages in Iran (3).

In recent decades, death rate from breast cancer has been decreasing (8), which is resulted from earlier detection by screening and progressing awareness of people about its signs and symptoms. So, one of the most important strategies in alleviating breast cancer mortality is screening in order to earlier detection (9).

Using guidelines for the early detection of breast can- cer can raise the chances of breast cancer diagnosis at an early stage and its successful treatment $(10,11)$. In addition, the evidence shows that women have limited knowledge about BC warning signs, risk factors, and screening programs (12).

In health care system of Iran, general physicians, who are responsible for a defined population with close contact with people, have an important role in implementing the breast cancer screening as one of the health ministry high priority programs.

\section{Objectives}

The objectives of this study were to find the amount of knowledge, and awareness in general physicians with regard to BC and its screening tests, in order to implement effective interventional programs in future. 


\section{Methods}

This cross sectional study was performed among 200 general physicians (GP) from urban and rural areas from Jun to September 2017 in Hamadan, Iran.

Sampling method was census and contained all GPs, who contracted as family physicians in Hamadan health center province. All of them were included in our study if they intended to participate and excluded if they spent special educational course period about cancer screening and risk factors.

A self-administered semi-structured questionnaire to take information about sociodemographic characteristics of participants and their knowledge about breast cancer was designed and its content validity was confirmed by an expert group, including an oncologist, 2 community and preventive medicine specialists, and the head of experts in cancer registration unit in Hamadan province health center. After agreement on the questionnaire, the piloting was done on a random sample of 20 physicians. So, the potential problems in the applicability of the tool were assessed.

The first section in questionnaire was included in questions about respondent's age, sex, location of work (rural or urban area), and the time interval after graduation. And the second part of questions contained participant's knowledge about breast cancer signs, symptoms, risk factors, and screening programs based on updated guidelines $(10,13,14)$.

All the correct responses to each question were given a score of 1 and the wrong answer or 'don't know' response were scored zero, respectively.

In order to determine the relationship between symptoms, risk factors, and screening programs awareness and some variables such as physician's sex, age, and work experience years, we compute related questions in every domain. So, high score showed high awareness.

The study begun after approval from institute's ethical committee (ID: IR.UMSHA.REC.1396.393). Consent to participate was obtained from all participant before collecting data.

Chi square test, Mann Whitney U test, and Spearman correlation were performed in data analysis, using SPSS version. 21. Significance level was set at $\mathrm{P}<0.05$.

\section{Results}

Among all 200 physicians, who had contract with Hamadan province health center, 150 persons completed questionnaires. All respondent's characteristics were shown in Table 1.
The mean score of total knowledge on breast cancer screening, risk factors, signs and symptoms for 23 questions was $15.07 \pm 2.4$ (max: 20 ; min: 9), which meant that correct answers were given to more than half of the questions.

In symptom awareness area, $45.3 \%$ of the physicians had correct answer to 4 questions, whereas about risk factor, $61.4 \%$ recorded correct answer to 8 questions. The highest knowledge score was related to breast cancer risk factors and the lowest was related to screening programs of breast cancer.

Figure 1 shows that all physicians knew lump and nipple retraction as symptoms of breast cancer also less than half, accounted "change in breast size, bloody nipple discharge, and breast pain" as symptoms (Figure 1).

More than $90 \%$ of general physicians knew that positive familial history and hormone replacement therapy (HRT) are considered as risk factors of breast cancer, while only $12.7 \%$ knew that there is an association between breastfeeding and breast cancer (Figure 2).

Regarding the screening methods, $45.3 \%$ of respondents selected correct answers on proper test for screening, 63.3\% on appropriate action in positive signs and symptoms, $28 \%$ on suitable age for screening, $44.7 \%$ on appropriate action in finding breast mass, and $60.7 \%$ on screening frequency and interval rules.

There was a significant reverse correlation between knowledge about screening programs and age of participants $(\mathrm{r}=-0.3 ; \mathrm{P}<0.001$; Figure 3$)$, and their years of work experience $(r=-0.26 ; P<0.001)$. Years of work experience had significant direct correlation with symptom knowledge of physicians as well $(\mathrm{r}=-0.1 ; \mathrm{P}=0.02)$. However, there were no significant difference in relationship between risk factor knowledge and sex, age and years of work experience (Table 2).

\section{Discussion}

All health staff and chiefly family physician's whom women may approach first, must be able to distinguish the risk factors, signs and symptoms, and screening programs of early cancer and must be able to refer patients for further diagnosis and treatment. So, their knowledge, attitude, and practices can predict the early diagnosis in communities (15).

The current study was performed on all family physicians in Hamadan province of Iran. It was observed that correct knowledge and its mean score about all the screening programs of breast cancer was very low and it was lower than median. In addition, there was a significant inverse correlation between screening programs knowledge and their ages and years of work experience. How- 


\begin{tabular}{|c|c|c|c|}
\hline Characteristic & Mean \pm SD & Range (Max - Min) & No. (\%) \\
\hline Age & $35.47 \pm 8.1$ & $55-25$ & \\
\hline Spent years after graduation & $9.4 \pm 7.8$ & $26-1$ & \\
\hline Years of work experience & $8.6 \pm 7.4$ & $26-1$ & \\
\hline \multicolumn{4}{|l|}{ Sex } \\
\hline Male & & & $70(46.7)$ \\
\hline Female & & & $80(53.3)$ \\
\hline \multicolumn{4}{|l|}{ Practice setting } \\
\hline Center of province & & & $36(24)$ \\
\hline Other districts & & & $114(76)$ \\
\hline
\end{tabular}

\begin{tabular}{|c|c|c|c|c|c|c|}
\hline \multirow{2}{*}{ Score } & \multicolumn{2}{|c|}{ Sex } & \multicolumn{2}{|c|}{ Age } & \multicolumn{2}{|c|}{ Work Experience Years } \\
\hline & Mean \pm SD & PValue $^{a}$ & $\mathbf{r}$ & PValue & $\mathbf{r}$ & P Value \\
\hline Symptom knowledge & & & 0.1 & 0.06 & 0.1 & 0.02 \\
\hline Male & $4.6 \pm 1.05$ & & & & & \\
\hline Female & $4.67 \pm 0.9$ & 0.3 & & & & \\
\hline Risk factor knowledge & & & 0.05 & 0.5 & 0.02 & 0.9 \\
\hline Male & $8.04 \pm 1.3$ & & & & & \\
\hline Female & $7.67 \pm 1.6$ & 0.2 & & & & \\
\hline Screening program knowledge & & & -0.3 & $<0.001$ & -0.26 & $<0.001$ \\
\hline Male & $2.3 \pm 1.3$ & & & & & \\
\hline Female & $2.5 \pm 1.2$ & 0.4 & & & & \\
\hline
\end{tabular}

${ }^{\mathrm{a}}$ Mann-Whitney test.

Correct Answers Percentage on Breast Cancer Warning Signs

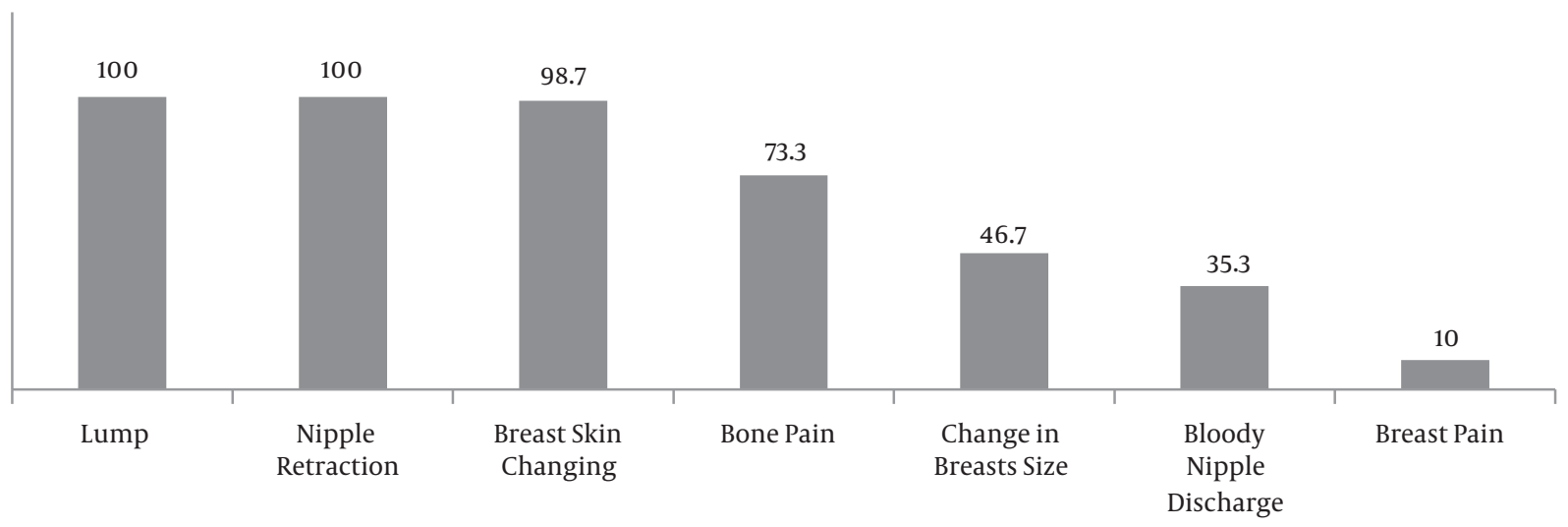

Figure 1. knowledge of Iranian family medicine physicians on symptoms of breast cancer

ever, physicians' knowledge about breast cancer risk factors was adequate and the most frequent true answers were about "family history" and HRT and the least were about the "effects of breastfeeding" and "age of pregnancy "and "touching a mass" in signs and symptoms questions. These findings about mentioned risk factors and breast- feeding as protective factor were similar to other related studies in Iran (16).

Sabatino et al. in a study on 50 to 75 years old women who had not get screening recently, showed that $70 \%$ of these women had not got advised from their physicians to do mammography (17). 


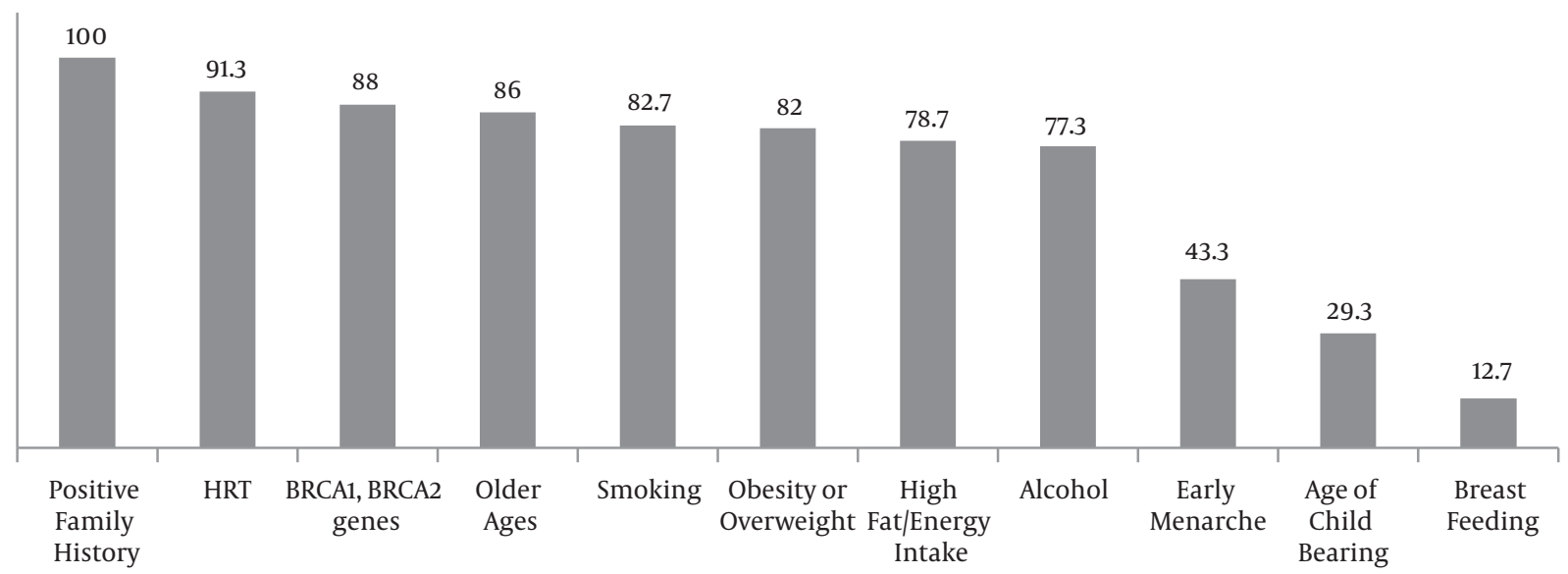

Figure 2. Knowledge of Iranian family medicine physicians on breast cancer risk factors

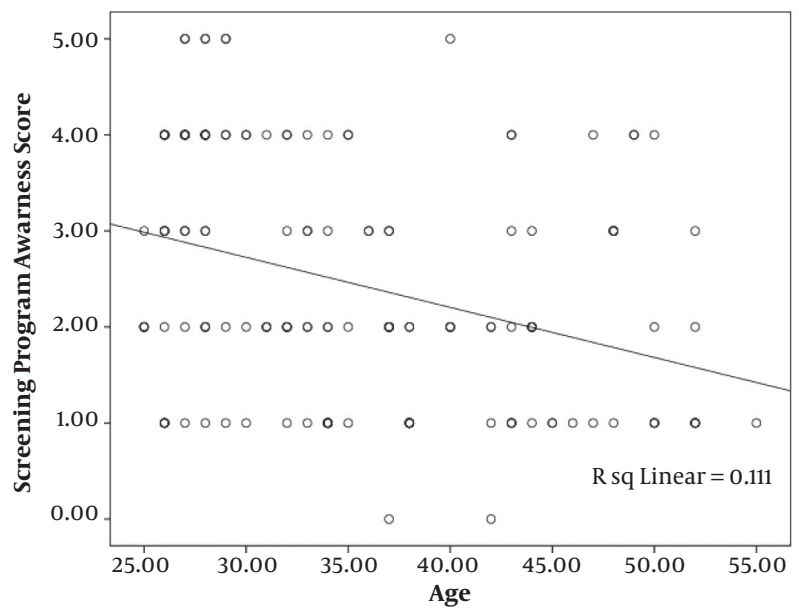

Figure 3. Correlation between age and screening programs awareness among family physicians

Meissne et al. in their study on 10212 women in 2007 showed that 3188 women had not received screening programs. They found out that $80 \%$ of the women, who had not done screening, had not been advised to do mammography and the problem has been advised for doing the screening; so, women probably did not request mammography by themselves. Among those who did not do screening programs, women of 40 to 49 years, those with lower education or women with lower income were more prevalent. Only a few percent of participants did not have screening due to access problems to health system (18).

In a study conducted by Smith et al. in Canada, $46 \%$ of the physicians reported that they routinely prescribe mammography for 40 to 49 years women and $40 \%$ believed that there is no necessity to do this. Also, $62 \%$ of physicians prescribed mammography if it was demanded from their patient and only $18 \%$ of physicians acted exactly like the protocol (19).

Vakili et al. carried out a study in Shiraz in 2010 about acceptance rate of screening programs in over 18 years population. They concluded that screening methods are used very lower than expected in population (20). This lower rate could possibly be justified by lack of information and advised for screening from physicians.

In Montazeri et al.'s study in Iranian women, it was concluded that Iranian women do not have sufficient information and knowledge about breast cancer risk factors and its screening methods and programs (21). In our study, even family physicians did not have sufficient information and knowledge about breast cancer risk factors and its screening methods and programs; although, the question types and contents for physicians and general population is definitely different. It was similar to Babapoor's findings, in which the physician's knowledge about breast cancer screening program was in a moderate level.

Findings of the present study emphasize the need to train Iranian physician's breast cancer screening programs to promote early identification of breast cancer. In a survey in Iran, significant increases in women knowledge about breast cancer were observed (22). Also, these kinds of studies on physicians are not sufficient in our country. Despite screening can lead to overtreatment, it can motivate women to participate in a preventive health strategy.

We recommend that there should be a well-designed 
health education program to compensate physicians' knowledge deficits, especially in older ages in order to raise knowledge toward cancer with emphasis on the role of prevention and screening. Probably, implementing breast cancer screening programs in physicians' training course can be helpful. In addition, it is useful to deliver educational booklets to physicians. Of course, the best method for training them can be issue in future researches.

However, in breast cancer screening, health manager's decisions and health policy as well as the cultural factors should be considered. Importance of early diagnosis in breast cancer and its high rate in our country are adequate reasons for considering this issue in top of our priorities.

In the current study, family physicians knowledge on breast cancer screening was insufficient. It is strongly recommended that there should be a well-designed health education program to compensate physicians' knowledge deficits, especially in older ages in order to raise knowledge toward cancer with emphasis on the role of prevention and screening. Importance of early diagnosis in breast cancer and its high rate in our country are adequate reasons for considering this issue in top of our priorities.

\section{Acknowledgments}

We gratefully acknowledge all health professionals and staff in health deputy of Hamadan province health center that helped for data collection.

\section{Footnotes}

Authors' Contribution: Azar Pirdehghan conceived and designed the evaluation, interpreted the clinical data, performed the statistical analysis, and helped to draft the manuscript and revised it. She also participated in designing the evaluation and helped to draft the manuscript. Parya Khosropour collected the data and Mohammad Ali Seif Rabiei helped to draft the manuscript. All authors read and approved the final manuscript.

Conflict of Interests: The authors declare that they have no conflict of interest.

Funding/Support: This article is derived from a MD thesis in medical school of Hamadan University of Medical Sciences.

\section{References}

1. Miller AB, Wall C, Baines CJ, Sun P, To T, Narod SA. Twenty five year follow-up for breast cancer incidence and mortality of the Canadian national breast screening study: Randomised screening trial. BMJ. 2014;348:g366. doi: 10.1136/bmj.g366. [PubMed: 24519768]. [PubMed Central: PMC3921437].
2. Saggu S, Rehman H, Abbas ZK, Ansari AA. Recent incidence and descriptive epidemiological survey of breast cancer in Saudi Arabia. Saudi Med J. 2015;36(10):1176-80. doi: 10.15537/smj.2015.10.12268. [PubMed: 26446327]. [PubMed Central: PMC4621722].

3. Nafissi N, Khayamzadeh M, Zeinali Z, Pazooki D, Hosseini M, Akbari ME. Epidemiology and histopathology of breast cancer in Iran versus other Middle Eastern countries. Mid East J Cancer. 2018;9(3):243-51.

4. McGuire S. World cancer report 2014. Geneva, Switzerland: World Health Organization, International Agency for Research on Cancer, WHO Press, 2015. Adv Nutr. 2016;7(2):418-9. doi: 10.3945/an.116.012211. [PubMed: 26980827]. [PubMed Central: PMC4785485].

5. Vakili M, Pirdehghan A, Adimi M, Sadeghian M, Akhondi M. Epidemiology and trend of cancer in Yazd, a central province of Iran, 2005-2009. J Res Health Sci. 2014;14(3):210-3. [PubMed: 25209908].

6. Mousavi SM, Gouya MM, Ramazani R, Davanlou M, Hajsadeghi $\mathrm{N}$, Seddighi Z. Cancer incidence and mortality in Iran. Ann Oncol. 2009;20(3):556-63. doi: 10.1093/annonc/mdn642. [PubMed: 19073863].

7. Mousavi SM, Montazeri A, Mohagheghi MA, Jarrahi AM, Harirchi I, Najafi $\mathrm{M}$, et al. Breast cancer in Iran: An epidemiological review. Breast J. 2007;13(4):383-91. doi: 10.1111/j.1524-4741.2007.00446.x. [PubMed: 17593043].

8. Siegel RL, Miller KD, Jemal A. Cancer statistics, 2017. CA Cancer J Clin. 2017;67(1):7-30. doi:10.3322/caac.21387. [PubMed: 28055103].

9. DeSantis C, Ma J, Bryan L, Jemal A. Breast cancer statistics, 2013. CA Cancer J Clin. 2014;64(1):52-62. doi: 10.3322/caac.21203. [PubMed: 24114568].

10. Oeffinger KC, Fontham ET, Etzioni R, Herzig A, Michaelson JS, Shih YC, et al. Breast cancer screening for women at average risk: 2015 Guideline update from the American Cancer Society. JAMA. 2015;314(15):1599-614. doi: 10.1001/jama.2015.12783. [PubMed: 26501536]. [PubMed Central: PMC4831582].

11. Smith RA, Andrews KS, Brooks D, Fedewa SA, Manassaram-Baptiste D, Saslow D, et al. Cancer screening in the United States, 2018: A review of current American Cancer Society guidelines and current issues in cancer screening. CA Cancer J Clin. 2018;68(4):297-316. doi: 10.3322/caac.21446. [PubMed: 29846940].

12. Ghodsi Z, Salehi A, Hojjatoleslami S. Knowledge of Iranian women about warning signs and risk factors for breast cancer. Proc Soc Behav Sci. 2013;93:343-8. doi:10.1016/j.sbspro.2013.09.201.

13. Asgari F, Mirzazadeh A, Heidarian H. Iran non communicable disease risk factors surveillance data book for 2007, National NCD Risk Factors Surveillance Committee. Iran NCD Risk Factors Steps Report; 2007.3 p.

14. Barnard ME, Boeke CE, Tamimi RM. Established breast cancer risk factors and risk of intrinsic tumor subtypes. Biochim Biophys Acta. 2015;1856(1):73-85. doi: 10.1016/j.bbcan.2015.06.002. [PubMed: 26071880].

15. Anderson BO, Yip CH, Smith RA, Shyyan R, Sener SF, Eniu A, et al. Guideline implementation for breast healthcare in low-income and middle-income countries: Overview of the Breast Health Global Initiative Global Summit 2007. Cancer. 2008;113(8 Suppl):2221-43. doi: 10.1002/cncr.23844. [PubMed: 18816619].

16. Akbari A, Razzaghi Z, Homaee F, Khayamzadeh M, Movahedi M, Akbari ME. Parity and breastfeeding are preventive measures against breast cancer in Iranian women. Breast Cancer. 2011;18(1):51-5. doi: 10.1007/s12282-010-0203-z. [PubMed: 20217489].

17. Sabatino SA, Burns RB, Davis RB, Phillips RS, McCarthy EP. Breast cancer risk and provider recommendation for mammography among recently unscreened women in the United States. J Gen Intern Med.2006;21(4):285-91. doi: 10.1111/j.1525-1497.2006.00348.x. [PubMed: 16686802]. [PubMed Central: PMC1484729].

18. Meissner HI, Breen N, Taubman ML, Vernon SW, Graubard BI. Which women aren't getting mammograms and why? (United States). Cancer Causes Control. 2007;18(1):61-70. doi: 10.1007/s10552-006-0078-7. [PubMed: 17186422]. 
19. Smith P, Hum S, Kakzanov V, Del Giudice ME, Heisey R. Physicians' attitudes and behaviour toward screening mammography in women 40 to 49 years of age. Can Fam Physician. 2012;58(9):e508-13. [PubMed: 22972742]. [PubMed Central: PMC3440292].

20. Vakili V, Danaei M, Abdollahifard G, Askarian M. Predictors of screening programs adherence: Report of a population based study in Shiraz, Iran. Int J Med Sci Public Health. 2014;3(9):1161. doi: 10.5455/ijmsph.2014.010720141.

21. Montazeri A, Vahdaninia M, Harirchi I, Harirchi AM, Sajadian A,
Khaleghi F, et al. Breast cancer in Iran: Need for greater women awareness of warning signs and effective screening methods. Asia Pac Fam Med. 2008;7(1):6. doi: 10.1186/1447-056X-7-6. [PubMed: 19099595]. [PubMed Central: PMC2628874].

22. Moodi M, Mood MB, Sharifirad GR, Shahnazi H, Sharifzadeh G. Evaluation of breast self-examination program using health belief model in female students.J Res Med Sci.2011;16(3):316-22. [PubMed: 22091251]. [PubMed Central: PMC3214340]. 